\title{
Revising the Belgian Nursing Minimum Dataset: From concept to implementation
}

\author{
Walter Sermeus ${ }^{a, *}$, Koen van den Heede ${ }^{a}$, Dominik Michiels ${ }^{a}$, \\ Lucas Delesie $^{\mathrm{a}}$, Olivier Thonon ${ }^{\mathrm{b}}$, Caroline Van Boven ${ }^{\mathrm{b}}$, \\ Jean Codognotto ${ }^{b}$, Pierre Gillet ${ }^{b}$
}

a Centre for Health Services Research, Catholic University of Leuven, Kapucijnenvoer 35/4, B-3000 Leuven, Belgium

b University Hospital of Liège, Liège, Belgium

\author{
KEYWORDS \\ Nursing Minimum \\ Dataset; \\ Nursing care \\ management; \\ Nursing Interventions \\ Classification; \\ Diagnostic related \\ groups
}

\begin{abstract}
Summary The process of revising the Belgian Nursing Minimum Dataset (B-NMDS) started in 2000 and entailed four major phases. The first phase (June-October 2002) involved the development of a conceptual framework based on a literature review and secondary data analysis. The Nursing Interventions Classification (NIC) was selected as a framework for the revision of the original B-NMDS. The second phase (November 2002-September 2003) focused on language development for six care programs evaluated by panels of clinical experts $(N=75)$. These panels identified the following items as priorities for the revised B-NMDS: hospital financing, nurse staffing allocation, assessment of the appropriateness of hospitalisation, and quality management. During this period, we developed a draft instrument with 92 variables using the NIC. This led to an alpha version of a revised B-NMDS. The third phase (October 2003-December 2004) focused on data collection and validation of the new tool. The revised B-NMDS (alpha version) was tested in 158 nursing wards in 66 Belgian hospitals from December 2003 until March 2004. This test generated data for some 95,000 in-patient days. The interrater reliability of the revised B-NMDS was assessed. The criterion-related validity of the revised B-NMDS was compared to that of the original B-NMDS. The discriminative power of the revised B-NMDS was also assessed to select the most relevant variables for data collection. This resulted in a beta version of the revised B-NMDS in December 2004. The records of the revised BNMDS were linked to the Hospital Discharge Dataset and other mandatory datasets to integrate the revised B-NMDS into the overall healthcare management system. The fourth phase (January 2005-December 2005) is presently focusing on information management. Nationwide implementation is foreseen by January 2007. (c) 2005 Elsevier Ireland Ltd. All rights reserved.
\end{abstract}

\footnotetext{
* Corresponding author. Tel.: +32 16336971; fax: +32 16336970

E-mail address: Walter.Sermeus@med.kuleuven.be (W. Sermeus).
}

\section{Introduction and background}

Belgium has a 15-year tradition of collecting hospital data, developing the Hospital Discharge Dataset 
(HDDS) in the 1980s. The HDDS was fully implemented in the 1990s. This dataset holds a set of relevant clinical information (primary and secondary diagnosis, procedures, length-of-stay, etc.) for each patient discharged from Belgian acute hospitals. Also, Belgium is still one of the few countries that complements its HDDS with a nationwide uniform Nursing Minimum Dataset (NMDS) for a balanced sample of in-patient days. The original Belgium NMDS (B-NMDS) allows the investigation of nursing care interventions and nurse staffing from 1987 onwards [1]. The mandatory registration resulted in an extensive dataset of more than 15 million selected in-patient days for some 6 million selected patients in 2500 nursing units accumulated over all Belgian hospitals. Nevertheless, applications in clinical practice and healthcare management are still limited and touch only a small part of the information available in the original B-NMDS. The main application of the original B-NMDS is to determine some percentage points of a hospital's budget. A few hospitals already use the dataset to guide their staffing decisions. On the other hand, the evolution of healthcare, and of nursing care in particular, demands that the original B-NMDS be updated. The Ministry of Public Health commissioned the Catholic University of Leuven and the University Hospital of Liège to revise the B-NMDS for six care programs (cardiology, oncology, geriatrics, chronic care, paediatrics, and intensive care) [2]. We began a study in 2000 to carry out this commission. The goal is to implement the revised B-NMDS in 2007.

The aim of this revision is to take into account the changes in nursing practice, the international development of nursing languages and classifications, the changes in healthcare management, and the need for integration of the B-NMDS with the HDDS.

\section{Methodology and procedure}

For the revision of the B-NMDS, a very strict plan was followed based on two main streams: (1) the use of panels of expert nurses and BNMDS coordinators to build an acceptable tool, and (2) the use of existing and new empirical nursing data to develop a high-quality tool that is valid and reliable. The project was divided into four major phases: (1) conceptualisation, (2) language development, (3) data collection and tool validation, and (4) information management. Each of these four consecutive phases is discussed below.

\section{Results}

\subsection{Phase I: development of the conceptual framework}

The first phase (June-October 2002) involved the development of a conceptual framework based on a literature review and secondary data analysis. The Nursing Interventions Classification (2nd edition) or NIC was selected as a framework for revising the original B-NMDS. The NIC is a comprehensive, research-based, standardised classification of interventions that nurses perform [3]. The 433 interventions in the NIC (2nd edition) are grouped into 27 classes and six domains for ease of use. This nursing language was selected for the revision of the B-NMDS because the NIC is based on strong validation work, exists in French and Dutch, is used internationally which allows further benchmarking, and has also been tested previously in Belgian home care [4]. The 2nd edition was used because an existing Dutch and French version of the classification is available in this edition. An update to the most recent version has already been discussed.

\subsection{Phase II: language development}

The second phase (November 2002-September 2003) focused on prioritising future application domains and language development for six care programs to be evaluated by panels of clinical experts $(N=75)$. Previous experience with the original B-NMDS highlighted the need to balance the considerable costs of registration with real-life improvements in nursing care and/or nursing management. It is plausible to propose only that new data be registered when the data of the original B-NMDS or other related datasets seem insufficient for updating existing indicators or for developing new ones.

Firstly, the panels of experts had to focus on the selection of meaningful nursing care and nursing management indicators rather than on individual data elements. They identified the following priorities to be addressed by the revised B-NMDS: hospital financing, nurse staffing allocation, assessment of the appropriateness of hospitalisation, and quality management. Secondly, the clinical experts of the six care programs selected the most relevant NIC interventions. All of them studied the NIC classification (2nd edition) [3]. They selected NIC interventions being used in their current practice and indicated the relevance of each of these interventions for inclusion in a future nursing minimum dataset along with the previously identified priorities. In total, 256 of 433 interventions were 
selected for at least one or more care programs. The research team translated these NIC interventions and the original B-NMDS variables into new $B-N M D S$ variables, defining them as response categories and registration requirements, respectively. All revised B-NMDS variables were listed in terms of the NIC framework in the appropriate domains and classes. The translation was carried out via an interactive process involving the research team and the panels of experts. The research team produced definitions, response categories, and registration requirements based on the information and suggestions given by the clinical panels of experts for each care program. Current clinical practice and desired practice (evidence-based nursing) were discussed. Each expert panel met at least five times, resulting in about 50 feedback sessions of $3-4 \mathrm{~h}$. Definitions included an unambiguous description of the nursing intervention, whereas response categories represented the level of nursing care (e.g., type, intensity, frequency, etc.). Registration requirements (e.g., documentation of intervention in patient records) were formulated to facilitate auditing of the registration.

This set of B-NMDS variables was pretested by the researchers in more than three wards per care program and in more than 15 different hospitals. This led to an alpha version of the revised B-NMDS having 92 variables.

\subsection{Phase III: pilot test and tool validation}

The third phase (October 2003-December 2004) focused on data collection, validation of the new tool, and integration with the HDDS.

\subsubsection{Data collection}

Hospitals were solicited to participate in the study for the six envisaged care programs. A total of 85 hospitals (69\% of all Belgian acute hospitals) with 244 nursing wards answered this call. For feasibility reasons, a selection was made based on the following well-defined selection criteria: equal regional and national distribution, balance between small and large hospitals, equal number of private and public hospitals, teaching and non-teaching hospitals, and an equal proportion of wards for each care program. Hence, 66 Belgian hospitals with 158 nursing wards were selected to participate in this test. Each hospital nominated a project coordinator responsible for organisation of education, data collection, data input, and data transmission to the research teams. These coordinators had previous experience with the original B-NMDS and with data handling.
The alpha version of the revised B-NMDS contained data from about 95,000 in-patient days obtained during 30 days and three registration periods (1-15 December 2003; 1-5 February 2004; 1-10 March 2004). The original B-NMDS and HDDS for patients assessed during this time period were also forwarded to the research team.

The feasibility of the revised B-NMDS (alpha version) was studied by measuring the time needed to collect the required data. This time assessment was done during the 4 days of the last two registration periods in 42 participating hospitals (81 nursing wards), resulting in a sample of 3504 in-patient days. The median time required for a revised B-NMDS coding was four minutes (interquartile range: $3-7 \mathrm{~min}$ ). The median time per care program ranged from 2 min (one day hospitalisation) to $8 \mathrm{~min}$ (intensive care). The median number of variables per in-patient day was 14 (range: 1-43), varying from a median score of 10 (1 day clinic stay) to a median score of 25 (intensive care).

\subsubsection{Reliability and validity}

Validity and reliability are important issues to consider when developing a new tool. In the present study, we investigated interrater reliability and criterion-related validity, construct validity, and content validity [5].

The interrater reliability of the revised B-NMDS was tested at three time points. Before each registration period the 66 coordinators were asked to score two written cases, describing the patient condition and nursing care given during one patient day. The six cases covered the six care programs and included 68 of the 92 variables of the alpha version of the revised B-NMDS. The research team developed a gold-standard score for each case. The scores of the respondents were compared with the gold-standard scores. The reliability score was calculated as the proportion of respondents who scored according to the gold-standard scores. Eighty percent of the revised B-NMDS variables had a reliability score of $70 \%$ or more.

The criterion-related validity of the revised BNMDS was compared with that of the original BNMDS. The goal of this approach was to objectively validate the revised B-NMDS in comparison to the original B-NMDS. The rationale for this approach was that the similar elements of the revised tool should give at least the same level and detail of information as the previously validated original BNMDS. Firstly, using common identifiers (hospital ID, registration date, nursing unit, anonymous patient number), we linked data collected with the revised tool during two of the three pilot periods to available data collected with the original B-NMDS. This 
Table 1 Results of the criterion-related validity assessment $(N=24,882)$ performed at the patient level

\begin{tabular}{|c|c|}
\hline Correlation & Variables \\
\hline$>0.80$ & Enteral tube feeding $(0.89)$, intake interview $(0.81)$ \\
\hline $0.61-0.80$ & $\begin{array}{l}\text { Oral health maintenance/restoration }(0.67) \text {, dressing (civil clothing) }(0.67) \text {, infection control } \\
\text { (isolation) }(0.62) \text {, pressure ulcer prevention }(0.75) \text {, medication administration IV }(0.63) \text {, blood } \\
\text { sampling }(0.79) \text {, self-care assistance: bathing/hygiene }(0.78) \text {, vital signs monitoring }(0.72)\end{array}$ \\
\hline $0.41-0.60$ & $\begin{array}{l}\text { Traction care }(0.57) \text {, feeding }(0.57) \text {, environmental management: safety and cognitive therapy } \\
(0.46)\end{array}$ \\
\hline $0.21-0.40$ & $\begin{array}{l}\text { Artificial airway management/oxygenation therapy }(0.39) \text {, teaching }(0.34) \text {, monitoring of clinical } \\
\text { signs }(0.31) \text {, emotional support }(0.24)\end{array}$ \\
\hline
\end{tabular}

resulted in a database of 24,882 records that was available for the comparison. After that, these linked data were recoded by the research team for 17 of the 23 variables of the original B-NMDS, so that the data definitions in both datasets were as similar as possible. Six original B-NMDS variables could not be sufficiently deduced from the revised B-NMDS. RIDIT analysis [6] was used to standardise these variables and to aggregate them for each nursing unit. Finally, correlation of the Spearman rho and Kendall's tau-b correlation coefficients were used to determine the criterion-related validity of the revised B-NMDS. The analysis was performed at three levels: patients, hospitals, and care programs. The correlations at the patient level (Table 1) ranged from 0.24 (emotional support) to 0.89 (tube feeding).

The discriminative power of the revised B-NMDS was tested to investigate the construct validity of the tool. We investigated how the variables of the revised B-NMDS (alpha version) measure the expected constructs described by the clinical experts during phase II of the project. This round of analysis aimed to reduce the variables to a manageable number and to use only these variables for nationwide registration that are a prerequisite for profiling nursing care for different pathology groups, nursing wards, and hospitals. The registration of the revised B-NMDS followed the NIC (2nd edition) classes. Each NIC class involves one or more variables. We analysed the data in two steps with principal component analyses (CATPCA ${ }^{\odot}$ ) using NIC as a framework. Firstly, data were analysed for each NIC class. These intra-class analyses led to the finding that the variables measured the same latent variable, the aggregation of some (hierarchical) variables, and the selection of variables with the highest discriminative power. Secondly, these analyses were repeated using inter-class analyses to investigate the association of variables between classes. Both types of analyses were done for each care program as well as on the total sample. This two-step round of analyses resulted in the follow- ing empirical-based recommendations: registration guidelines and distinction between general, careprogram specific, and non-relevant variables.

Finally, the content validity of selected BNMDS variables was determined by presenting the instrument to clinical experts (October-November 2004). They discussed the results of the study and suggested improvements based on their clinical expertise and nursing care management experience. The most frequent reasons to suggest the inclusion of variables rejected by the initial analyses of the revised B-NMDS were quality monitoring, significant impact on nursing workload, and the indication that analyses results were biased by a select study sample. The final set was composed of a core dataset of 37 variables, complemented by $11-19$ variables depending on the specific care program (Table 2 ).

The beta version of the revised B-NMDS was tested March 2005 in general internal medicine (15 wards) and surgical wards (15 wards) to assess the suitability of the instrument for these wards for 10 consecutive days (1 March 2005-10 March 2005); this was performed in parallel with a registration of the original B-NMDS.

On request of the Ministry of Public Health and the Belgian Hospitals, we extended the revised $\mathrm{B}$ NMDS to include maternity care wards (20 wards). Prior to the pilot test of March 2005, a panel of clinical experts suggested new B-NMDS variables for maternity care based on the NIC classes W (childbearing care) and X (lifespan care).

The final revised B-NMDS is targeted for approval in September 2005 by a commission appointed by the Federal Government of Public Health. They will select the variables for the final revised B-NMDS based on the results of the present study.

\subsubsection{Integration of the revised B-NMDS with the HDDS}

The revised B-NMDS records were linked with the HDDS. By linking both datasets, we aimed to develop a methodology to link nursing data with 
Table 2 Proposed variables for the revised B-NMDS (beta version)

\begin{tabular}{|c|c|}
\hline Datasets & Variables \\
\hline Core dataset (37 variables) & $\begin{array}{l}\text { Toileting urinary; toileting bowel; elimination training (urinary and bowel); } \\
\text { bed rest care; positioning; transport (inside nursing ward); feeding; enteral } \\
\text { tube feeding; TPN; pain management; nausea management; self-care } \\
\text { assistance: hygiene/bathing; oral health maintenance/restoration; in/out } \\
\text { measurement (fluids/food); administration medication IM/SC/ID; } \\
\text { administration medication IV; aerosol; artificial airway management; } \\
\text { mechanical ventilation; wound care: suture, drains \& osteosynthesis } \\
\text { equipment, pressure ulcer care; wound care: open complex; access points (IV; } \\
\text { SC; arterial); arterial blood sampling; venous blood sampling; capillary blood } \\
\text { sampling; cognitive therapy; emotional support; teaching (not specified } \\
\text { elsewhere); teaching: preoperative/procedures; pressure ulcer prevention } \\
\text { (dynamic alternating material); pressure ulcer prevention (positioning); vital } \\
\text { signs monitoring (continuous); vital signs monitoring (discontinuous); infection } \\
\text { control (isolation); intake interview; multidisciplinary meeting }\end{array}$ \\
\hline \multicolumn{2}{|c|}{ Supplementary datasets for specific care programs } \\
\hline $\begin{array}{l}\text { Geriatric care (11 additional } \\
\text { variables) }\end{array}$ & $\begin{array}{l}\text { Exercise therapy (physical); urinary catheterisation; constipation/impaction } \\
\text { management; dining room; training hygiene/bathing; dressing (civil clothing); } \\
\text { self-image management; activity therapy; diagnostic sampling; assessment; } \\
\text { health care information exchange: extra muros }\end{array}$ \\
\hline $\begin{array}{l}\text { Chronic care (16 additional } \\
\text { variables) }\end{array}$ & $\begin{array}{l}\text { Exercise therapy (physical); urinary catheterisation; constipation/impaction } \\
\text { management; transport (outside nursing ward); dining room; fatigue } \\
\text { management; training hygiene/bathing; dressing (civil clothing); bath/shower; } \\
\text { self-image management; activity therapy; communication enhancement; } \\
\text { diagnostic sampling; environmental management: safety; assessment; health } \\
\text { care information exchange: extra muros }\end{array}$ \\
\hline $\begin{array}{l}\text { Oncology care (15 additional } \\
\text { variables) }\end{array}$ & $\begin{array}{l}\text { Constipation/impaction management; transport (outside nursing ward); } \\
\text { fatigue management; self-image management; tube care: gastrointestinal; } \\
\text { hyper/hypo glycaemia management; airway suctioning; wound care: open } \\
\text { simple; blood products administration; communication enhancement; } \\
\text { diagnostic sampling; family involvement promotion, assessment; physician } \\
\text { support; health care information exchange: extra muros }\end{array}$ \\
\hline $\begin{array}{l}\text { Cardiology care ( } 9 \text { additional } \\
\text { variables) }\end{array}$ & $\begin{array}{l}\text { Transport (outside nursing ward); hyper/hypo glycaemia management; } \\
\text { electrolyte/acid-base management; airway suctioning; wound care: open } \\
\text { simple; temporary pacemaker (external) management; cultural brokerage; } \\
\text { physician support; healthcare information exchange: extra muros }\end{array}$ \\
\hline $\begin{array}{l}\text { Paediatric care (19 additional } \\
\text { variables) }\end{array}$ & $\begin{array}{l}\text { Elimination management child < } 5 \text { years; urinary catheterisation; transport } \\
\text { (outside nursing ward); dining room; bottle feeding; sedation management; } \\
\text { bath/shower; tube care: gastrointestinal; hyper/hypo glycaemia management; } \\
\text { electrolyte/acid-base management; neurologic monitoring: Glasgow Coma } \\
\text { Scale; airway suctioning; wound care: open simple; wound care: } \\
\text { dermatologic; blood products administration; activity therapy; diagnostic } \\
\text { sampling; environmental management: safety; family involvement promotion }\end{array}$ \\
\hline $\begin{array}{l}\text { Intensive care (16 additional } \\
\text { variables) }\end{array}$ & $\begin{array}{l}\text { Transport (outside nursing ward); traction care; sedation management; tube } \\
\text { care: gastrointestinal; electrolyte/acid-base management; dialysis therapy; } \\
\text { neurologic monitoring: Glasgow Coma Scale; intracranial pressure monitoring; } \\
\text { wound care: open simple; blood products administration; communication } \\
\text { enhancement; temporary pacemaker (external) management; circulatory } \\
\text { care: mechanical assistance; diagnostic sampling; family involvement } \\
\text { promotion; physician support }\end{array}$ \\
\hline
\end{tabular}

diagnostic related groups (DRGs) in a logical and meaningful way. This linking will ultimately produce new information, e.g., variability of nursing care per DRG, the impact of reduction in length-of-stay on nurse staffing, etc.

\subsection{Phase IV: developing information management applications}

The fourth phase (January 2005-December 2005) focuses on information management. Applications 
for hospital financing and nurse staff allocation are currently being developed. The revised B-NMDS will be used to evaluate appropriate in-hospital stay. Feedback and audit modules will be built. Information and Communication Technology (ICT) support in collecting and analysing the data will be developed. Legislation to allow this revised data collection will be adapted and a final version prepared in time for nationwide implementation in January 2007.

\section{Conclusions}

A reason why so few NMDS are in use worldwide, is presumably the fact that they are hard to accomplish: identifying and involving various stakeholders such as nurses, policy makers, healthcare managers, other healthcare professionals; building consensus among them on goals, standards, variables; creating the "legal" framework by developing procedures for data collection, monitoring and audit, access, confidentiality; implementing the dataset by providing tools for data collection, national databases; training of nurses and data collectors; using the data by developing applications meeting the needs of all stakeholders.

Our experience was that revising the dataset was even harder to accomplish. But the systematic approach by involving the stakeholders from start to finish and building trust on the one hand and the hard facts from the data collection on the other hand seemed to be successful.

\section{Acknowledgment}

Revision of the B-NMDS was supported and financed by the Belgian Federal Ministry of Social Affairs, Public Health, and the Environment.

\section{References}

[1] W. Sermeus, L. Delesie, J. Van Landuyt, Y. Wuyts, G. Vanden Boer, The Nursing Minimum Data Set in Belgium: A Basic Tool for the Tomorrow's Health Care Management, Ministerie van Volksgezondheid en Leefmilieu and Centrum voor Ziekenhuiswetenschap, Brussel/Leuven, 1994.

[2] W. Sermeus, L. Delesie, K. Van Den Heede, Updating the Belgian Nursing Minimum Data Set: framework and methodology, Stud. Health Technol. Inform. 93 (2002) 8993.

[3] J.C. McClosky, G.M. Bulechek, M.C. Craft-Rosenberg, J. Daley, J. Denehey, O. Glick, Nursing Interventions Classification (NIC), 2nd ed., Mosby-Year Book, Inc., St. Louis, 1996.

[4] K. De Vliegher, E. Legiest, L. Paquay, L. Wouters, R. Debaillie, L. Geys, Kerninterventies in de thuisverpleging, Wit-Gele Kruis, Brussel, 2003.

[5] D.F. Polit, B.P. Hungler, Nursing Research, Principles and Methods, 5th ed., Lippincott Company, Philadelphia, 2005.

[6] W. Sermeus, L. Delesie, Ridit analysis on ordinal data, West J. Nurs. Res. 18 (1996) 351-359.

Available online at www.sciencedirect.com

science@Direct 